\title{
HISTÓRIA, QUADRINHOS E IDEOLOGIA: O COMPLEXO INDUSTRIAL-MILITAR EM THE BOYS
}

\author{
HISTORIA, COMICS Y IDEOLOGÍA: EL COMPLEJO \\ MILITAR-INDUSTRIAL EN THE BOYS
}

\section{HISTORY, COMICS AND IDEOLOGY: THE INDUSTRIAL- MILITARY COMPLEX IN THE BOYS}

\author{
Janaina de Paula do Espírito Santo \\ janainapes@gmail.com \\ Universidade Estadual de Ponta Grossa \\ Lucas Patschiki \\ lucas.patschiki@gmail.com \\ Universidade Estadual do Oeste do Paraná
}

\begin{abstract}
Resumo: Neste artigo iremos abordar as relações entre o Estado e a iniciativa privada no complexo industrial-militar, a partir do quadrinho The BOYS (em português: Os RAPAZES), escrito por Garth Ennis e desenhado por Darick Robertson, especificamente o arco I tell you no lie G.I. (em português: Eu não conto mentiras, soldado), números 19 até 22 da série, lançados em 2008 pela editora Dynamite Entertainment, que dá conta do desenvolvimento do complexo industrial-militar estadunidense na segunda metade do século XX. Exploraremos como as percepções históricas e sociais veiculadas por este produto cultural pode servir para desvelar as relações de expropriação, exploração e dominação que perpassam este processo histórico, buscando também refletir sobre as relações entre os quadrinhos, um produto da indústria cultural, e a ideologia na produção de discursos críticos sobre a realidade social.
\end{abstract}

Palavras-chave: História em quadrinhos. Complexo industrial-militar. Garth Ennis. Darick Robertson.

Resumen: En este artículo se discute la relación entre el Estado y la empresa privada en el complejo militar-industrial, de los comics The BOYS (en portugués Os RAPAZES), escritos por Garth Ennis y el artista Darick Robertson, específicamente el arco I tell you no lie GI (en portugués Eu não conto mentiras, soldado), números 19 a 22 de la serie, lanzados en 2008 por la editorial Dynamite Entertainment, que da cuenta del desarrollo del complejo militar-industrial de EE.UU. en la segunda mitad del siglo XX. Explora cómo las percepciones históricas y sociales transmitidas por este producto cultural puede servir para revelar las relaciones de expropiación, la explotación y la dominación que subyacen a este proceso histórico, buscando también reflexionar sobre la relación entre el cómic, un producto de la industria cultural, y la ideología en la producción de los discursos críticos sobre la realidad social.

Palabras Claves: Comics. Complejo militar-industrial. Garth Ennis. Darick Robertson. 


\begin{abstract}
In this article we address the relations between the State and private initiative in the industrial-military complex, in the comic The BOYS (in Portuguese Os RAPAZES), written by Garth Ennis and drawn by Darick Robertson.Specific attention is paid to the story arc I tell you no lie G.I. (in Portuguese Eu não conto mentiras, soldado), in numbers 19 through 22 of the series, which was published in 2008 by Dynamite Entertainment, and which gives an account of the development of the U.S. military-industrial complex in the second half of the twentieth century. We explore how the historical and social perceptions conveyed by this cultural product may serve to uncover the relationships of expropriation, exploitation and domination that pervade this historical process. We also discuss the relationship between comics, which are a product of the cultural industry, and ideology in the production of critical discourses about social reality.
\end{abstract}

Keywords: Comics. Industrial-military complex. Garth Ennis. Darick Robertson.

\title{
INTRODUÇÃO
}

Os quadrinhos conheceram, nos últimos anos, importante reconhecimento acadêmico, o que obviamente não ocorreu e nem ocorre sem resistências. É como parte desta 'nova visibilidade' que nos propomos pensar criticamente The BOYS, obra criada por Garth Ennis, roteirista, e por Darick Robertson, desenhista principal, especificamente o arco I tell you no lie G.I. (Eu não conto mentiras, soldado), números 19 até 22 da série, lançados em 2008 pela editora Dynamite Entertainment ${ }^{1}$. As análises acadêmicas sobre quadrinhos acabam por elegê-los para a análise de seu conteúdo (caso de quando apreendido como fonte histórica) ou de suas formas (caso das pesquisas que buscam compreender suas possibilidades pedagógicas). Neste trabalho, mesmo que somente apresentando reflexões iniciais, iremos buscar escapar dos termos desta cisão (que são válidos e necessários, assinale-se), procurando entendê-los organicamente. Assim, trataremos os quadrinhos como um produto cultural artístico, historicamente situado, que pode servir para desvelar as relações de expropriação, exploração e dominação que perpassam seu processo de criação, produção, distribuição e consumo.

As inovações tecnológicas, especialmente após a segunda década do século XX, alteraram drasticamente as relações entre a arte e os indivíduos. Buscando compreender este deslocamento do lugar social da arte, Theodor W. Adorno e Max Horkheimer formularam o conceito de indústria cultural, a consideração teórica para a produção artística e cultural em linha, industrializada. Esta perspectiva busca explicitar o papel fundamental do mass media na reprodução ampliada do capital, possibilitando uma nova escala qualitativa e de alcance para a organização da dominação, não se limitando a aumentar o fluxo de informação mas também modelando suas formas. No entanto, ainda que estes autores propusessem importantes reflexões em relação à sociedade mediatizada, através da dialética do esclarecimento, suas proposições afirmaram a cultura de massas como inferior, menor, diante de outras formas artísticas. Isto fez com que a análise de

1 Não poderíamos deixar de agradecer Von Dews e toda equipe do VertigemHQ!, responsáveis pelas primeiras traduções de The BOYS em português. 
produtos da indústria cultural passasse a encará-los com certa desconfiança, minimizando seu impacto social.

Esta postura teórica foi criticada já no interior da Escola de Frankfurt, sendo que, para Walter Benjamin (2000), estas novas expressões artísticas possuem potencialidades subversivas, fundamentadas na reprodução técnica. A potencialidade artística e social da cultura de massa advém exatamente das descaracterizações realizadas contra antigas definições de arte, especialmente em torno da sua autenticidade, valor e culto. Para Benjamin, a arte pré-moderna atendia a um caráter ritual, religioso, tendo seu valor de culto definida pela singularidade e unicidade; ao destruir-se a 'aura' da arte, ela ganha nova amplitude expositiva pela difusão em massa, pela produção em série. A difusão artística minimiza a elitização da produção específica, socializando, de certa maneira, o acesso à arte. Neste momento, a cópia deixa de ser falsificação ou plágio para converter-se em artigo 'original', mesmo que não seja único. As necessidades do mercado possibilitaram que os quadrinhos deixassem de ser a obra de um único artista, passando a ter um roteirista, um desenhista, um arte-finalista, e assim por diante. A rapidez assegurada pela produção em linha, marcada pelo tempo do capital, passaram a determinar esses produtos: a reprodução define os quadrinhos para além de um conjunto de características descritivas comuns entre eles. As histórias em quadrinhos são apontadas como uma síntese do processo analisado por Benjamin, tanto por suas especificidades estéticas quanto por suas possibilidades de consumo. "Quem é o criador de uma página de histórias em quadrinhos que foi escrita por uma pessoa, desenhada por outra, e que teve arte-final, letreiramento (e talvez até colorido e fundo) feitos por outras pessoas ainda?" (EISNER, 1989, p. 123).

Descritivamente uma história em quadrinhos é composta, habitualmente, por uma superfície ou uma série de superfícies, em formato quadrado ou retangular, que quando exploradas graficamente podem ser chamadas de quadrinhos (ou vinhetas). Estas são delimitadas por traços perpendiculares que, seccionando a página, justapõem os quadrinhos, estruturando a ordem das narrativas gráficas e narrativas. Assim a forma de leitura escapa da linearidade para ser guiada pela distribuição dos elementos visuais na superfície da página:

Os quadrinhos, como o próprio nome indica, são um conjunto e uma sequência. O que faz do bloco de imagens uma série é o fato de que cada quadro ganha sentido depois de visto o anterior; a ação contínua estabelece a ligação entre as diferentes figuras. Existem cortes de tempo e espaço, mas estão ligados a uma rede de ações lógicas e coerentes [...] Uma característica vital foi acrescentada à representação das imagens: o tempo passava a ser um elemento de organização da série. (KLAWA; COHEN, 1977, p. 110).

Esta relação entre imagem, narração e tempo, junto com a natureza de mídia de baixo custo e grande divulgação, foram responsáveis pelo seu forte impacto cultural. Os quadrinhos se consolidaram como elemento de cultura de massas entre os anos 1920 e 1930 nos Estados Unidos, ao mesmo tempo em que seu espaço regulador, o King Features 
Syndicate. O estilo das histórias foi adaptando-se diante das transformações históricas e sociais e dos contextos aos quais se dirigiram. No período de 1940 até 1945, por exemplo, os super-heróis viveram ficcionalmente os conflitos armados, as missões de guerra (somente neste período foram criados aproximadamente quatrocentos super-heróis). Nos anos seguintes, os chamados 'anos de ouro' do capitalismo ocidental, esta produção massificou-se ainda mais, passando a abarcar novos mercados e temas políticos e sociais, do anticomunismo até os direitos civis. Mas a partir da década de 1960, com a emergência de produções underground (que circulavam em fanzines, editorados de forma amadora), os quadrinhos conhecem novas temática e público. Esse processo de diversificação atinge seu ápice nos anos 1970, com o emergência de autores como Robert Crumb, Gilbert Shelton, S. Clay Wilson, Victor Moscoso e Bill Griffin. Mas o que começou como uma reação aos padrões editoriais vigentes, será, ao longo das próximas décadas, assumido pela indústria dos quadrinhos como um nicho de mercado específico, do 'quadrinho autoral' ou 'de colecionador'.

Este movimento não se resumiu aos Estados Unidos, pois na Europa, em 1974, desenhistas franceses como Moebius, Phillipe Druillet, Jean Pierre Dionnet, e Bernard Farkas, reunidos na Les humanoïdes associés, criaram a revista Métal hurlant, que irá explorar e definir novos limites para a arte em quadrinhos. Suas histórias são marcadas pela abordagem fantástica, englobando ficção cientifica, literatura, viagens psicodélicas, rock' $n^{\prime}$ roll, corpos nus, novas diagramações, mix propositadamente plural e que alcançou rápido sucesso. Na Itália surgiram títulos marcantes, já criados para um público adulto, como Ken Parker, de Berardi e Milazzo, Corto Maltese, de Hugo Pratt, e O clic, de Milo Manara.

Os anos 1980 marcam o aparecimento do graphic novel (romance gráfico), e o carrochefe dessa nova linha editorial foi $O$ cavaleiro das trevas, que narra a história de um Batman sombrio e violento, decretando a maioridade no mundo dos super-heróis. Seu autor, Frank Miller, apontou como sua principal influências um gekigá (termo japonês cuja tradução literal é 'figuras dramáticas', termo usado para definir um tipo adulto de mangá), chamado Lobo solitário, de Kazuko Koike, que narra a história de um samurai perturbado emocionalmente, agressivo.

Nos anos 1990 as maiores editoras estadunidenses, a Marvel e a DC comics, perderam seus principais desenhistas (estes eram contratados por trabalho, eram freelances, e eram obrigados a dividir os direitos autorais de suas criações com os estúdios), que fundaram a Image Comics. Esta nova editora foi um sucesso instântaneo, o que em parte deveu-se aos currículos de seus fundadores: Todd McFarlane, Jim Lee, Rob Liefeld, Marc Silvestri, Erik Larsen, Jim Valentino, Whilce Portacio e Chris Claremont. As produções da Image (Spawn, The Darkness, Youngblood, Savage Dragon etc.) afirmaram duas inovações que se generalizaram nas histórias em quadrinhos de influência estadunidense: a colorização computadorizada e a influência dos mangás na caracterização dos personagens.

Atualmente a influência dos mangás nas publicações de quadrinhos ocidentais é um fato, transformação que nos parece duradoura. Uma espécie de adaptação do mercado editorial ocidental diante do sucesso globalizante que os mangás passaram a apresentar desde o fim dos anos 1980. Sobre isto, pesquisas desenvolvidas pela Divisão de Economia 
Japonesa (JETRO, 2005) registram um crescente aumento no consumo de mangás pelo Ocidente. No Brasil, editoras como a Panini, JBC e Conrad ampliam anualmente seus catálogos, investindo em títulos destinados a uma grande diversidade de público. A presença deste modelo midiático torna-se marcante, rivalizando agressivamente com os modelos de novelas gráficas tradicionais, agrupados de modo genérico sob a rubrica de 'histórias em quadrinhos'.

Hoje, mesmo com a queda do consumo, especialmente comparado com a produção dos anos 1960, o alcance da produção da nona arte ainda é considerável, sendo o Brasil o quinto maior mercado consumidor total de quadrinhos. Sobre estes consumidores, em pesquisa supervisionada por Victor Trujillo durante o I Festival de HQ e Universo Fantástico, em 21, 22 e 23 de setembro de 2001 em Campinas, São Paulo, verificou-se que $85 \%$ é do sexo masculino, a maioria com segundo grau completo (52\%), 18,5\% com o primeiro grau completo e $25 \%$ possuindo titulação universitária (somente 3,7 do total com pós-graduação), 8,1\% começaram a ler quadrinhos durante a alfabetização, mais da metade (51\%) leem histórias em outras línguas, $42 \%$ dos entrevistados acreditam que os quadrinhos influenciam na formação de sua opinião, e outros 34\% afirmaram que estas influenciam a sua vida social como um todo (MUNDOHQ, 2013).

\section{PRODUTOS ARTÍSTICO-CULTURAIS E IDEOLOGIA}

Na sociedade de classes o conhecimento, sua produção, divulgação e ensino são condicionados pelas exigências da reprodução ampliada do sistema: as classes produtoras são expropriadas do conhecimento sobre o trabalho, caso mais visível (mas não resumido) no trabalhador manual. É atribuído ao trabalhador intelectual, o especialista, tanto o conhecimento autorizado sobre a produção, sobre a maquinaria e sobre os padrões de exploração ditadas pela gestão produtiva (embora efetivamente nem o trabalhador intelectual, e muito menos o patrão, sejam dotados da experiência prática), quanto na produção ideológica: as formas de mistificação e deturpação consciente do real. Motivo pelo qual foram dotados de um status específico em relação a sua condição de classe, especificamente nos últimos cinquenta anos, que conheceram excepcional crescimento das superestruturas. O que de modo algum significa que o campo ideológico reproduza-se sem conflitos e contradições, que estes intelectuais atuem como um bloco, oferecendo explicações monistas e/ou simplórias, embora assinalando que a 'autonomia relativa' do campo da produção ideológica (linguagem, tempo, agentes especialistas) explicita o engendramento da técnica na forma nos propósitos hegemônicos:

Seria um erro insinuar que a crítica marxista se move mecanicamente do "texto", para a "ideologia", para as "relações sociais" e então para "as forças produtivas". Ela lida, em vez disso, com a unidade desses "níveis da sociedade". É verdade que a literatura faz parte da superestrutura, mas ela não é apenas um reflexo passivo da base econômica. Engels esclareceu esse ponto em uma carta a Joseph Bloch em 1890 [...] os elementos da superestrutura reagem constantemente à base econômica e o 
influenciam. A teoria materialista da História nega que a arte possa, por si só, mudar o curso da História; mas ela insiste que a arte pode ser um elemento ativo em tal mudança. (EAGLETON, 2011, p. 24-25).

O conteúdo, mesmo condicionado pelo mercado em sua constituição, conhece uma autonomia maior que a de ser 'mero' reprodutor das representações da classe dominante, até porque esta é fracionada, afirmando representações distintas de seu lugar social. "A arte encontra-se imersa em ideologia, mas também consegue distanciar-se dela, a ponto de nos permitir 'sentir' e 'observar' a ideologia de onde surge" (EAGLETON, 2011, p. 39). A diferença entre ciência e arte, "não é que elas lidam com objetos de estudo diferentes, mas que lidam com os mesmos objetos de modo diferente", pois, enquanto "a ciência nos fornece conhecimento conceitual de uma situação; a arte nos proporciona a experiência dessa situação, que é equivalente à ideologia. Mas ao fazer isso, ele nos permite 'ver' a natureza dessa ideologia", deste modo encaminhando o sujeito "ao entendimento completo da ideologia, que é o conhecimento científico" (Idem, p. 39). Nesta consideração, a superestrutura não é uma instância deslocada da base, e muito menos uma simples emanação desta, como se esta fosse uma relação mecanicista, ela é uma metáfora que indica a relação dialética e histórica entre o mundo material e suas formas espirituais - indicando que esta separação é metodológica, na realidade este processo ocorre de maneira orgânica. Ela é a mediação ideológica que tem como chão social as relações de produção - neste sentido, podemos considerá-la como parte da 'ideologia histórica' que engendra os indivíduos, mediando suas possibilidades de ação.

Os autores aqui considerados podem ser entendidos como intelectuais, no sentido que Antonio Gramsci conceitua. Mesmo como artistas produzem e divulgam uma visão de mundo, um discurso ideológico que, ainda que não se pretendendo diretamente político, são engendrados e condicionados pelas suas bases históricas e sociais. Assinalando a:

[...] frequente afirmação de Marx sobre a "solidez das crenças populares" como elemento necessário de uma determinada situação. Ele diz mais ou menos isto: "quando esta maneira de conceber tiver a força das crenças populares", etc. Outra afirmação de Marx é a de que uma persuasão popular tem, com frequência, a mesma energia de uma força material, ou algo semelhante, e que é muito significativa. A análise destas afirmações, creio, conduz ao fortalecimento da concepção de "bloco histórico", no qual, precisamente, as forças materiais são o conteúdo e as ideologias são a forma, distinção entre forma e conteúdo meramente didática, já que as forças materiais não seriam historicamente concebíveis sem forma e as ideologias seriam fantasias individuais sem as forças materiais. (GRAMSCI, 1999, p. 238).

A conceituação gramsciana de intelectual afirma-se contra a concepção burguesa de intelectual, definida pelo preenchimento de certos parâmetros ideais para tal caracterização, pois para Gramsci, ao contrário, "em qualquer trabalho físico, mesmo no mais mecânico e mais degradado, existe um mínimo de qualificação técnica, isto é, um mínimo de atividade intelectual criadora" (GRAMSCI, 2004, p. 18-19), tornando impossível "separar o homo faber do homo sapiens" (Idem, p. 52-53). Isto permite-lhe argumentar que 
é "possível dizer que todos os homens são intelectuais, mas nem todos os homens têm na sociedade a função de intelectuais", que "as categorias especializadas para o exercício da função intelectual" foram historicamente formadas "em conexão com todos os grupos sociais, mas sobretudo em conexão com os grupos sociais mais importantes, e sofrem elaborações mais amplas e mais complexas em ligação com o grupo social dominante" (Idem, p. 18-19). É preciso enfatizar esta questão, pois a relação dos intelectuais com a organização social não ocorre dissociada das classes sociais, alheia à sua posição de classe no modo de produção, sendo "'mediatizada', em diversos graus, por todo o tecido social, pelo conjunto das superestruturas, do qual os intelectuais são precisamente os 'funcionários'”. Muitos autores utilizam a passagem acima para cindir a sociedade civil e política do mercado, do terreno da produção e distribuição. Isto tornaria o Estado e seus funcionários alheios à estrutura, tomando-os somente como responsáveis pela gestão das formas de exploração, reduzindo as relações sociais a uma base mecanizante, automática - para não dizer idealista. "A elaboração das camadas intelectuais na realidade concreta não ocorre num terreno democrático abstrato, mas segundo processos históricos tradicionais muito concretos" (Idem, p. 20), o que possui consequências diretas sobre sua relação com as classes sociais fundamentais. Os intelectuais não se constituem em casta, sendo que se sua diferenciação refere-se pela clivagem classista e da divisão social do trabalho: "a própria função organizativa da hegemonia social e do domínio estatal dá lugar a uma certa divisão do trabalho e, portanto, a toda uma gradação de qualificações" (Idem, p. 21).

Novamente, estas relações são mediadas pelo lugar específico de seus conflitos, mas é determinada pela luta de classes, portanto, podemos atentar para as brechas e possibilidades oferecidas pela relação de forças para atuar conscientemente para que o conhecimento da realidade torne-se possibilidade de libertação (o que significa que todo projeto editorial é também um projeto ético-político), através da explicitação dos marcos constitutivos da dominação - validade que resguarda a função dos trabalhos que buscam viabilizar os quadrinhos como instrumentos de pedagogia crítica. Esta questão é reconhecida na base do que Pierre Bourdieu conceitua como violência simbólica, que articula-se à hegemonia para a manutenção desta (MENDONÇA; FONTES, 2002. p. 67), que, como fator decisivo, "só pode se desenvolver e ser eficaz sobre o fundo do desconhecimento: na e pela ignorância da qual ela é objeto" (QUINIOU, 2000, p. 58), ou seja, "só pode se exercitar sobre sujeitos cognoscentes, mas cujos atos de conhecimento, parciais e mistificados, contêm o reconhecimento tácito da dominação que está implicada no desconhecimento dos fundamentos verdadeiros da dominação" (Idem, p. 58). Já afirmamos que a arte encontra-se imersa em ideologia, mas, aqui, o que buscamos enfatizar é a capacidade de libertação que pode existir na forma e estrutura que o artista consegue manejar na experiência ideológica comum dos homens, transformando-a, "dando à ideologia uma forma determinada, fixando-a dentro de certos limites ficcionais, que a arte é capaz de distanciar-se dela, revelando-nos assim o limite dessa ideologia" (EAGLETON, 2011, p. 40). 


\section{GARTH ENNIS E DARICK ROBERTSON}

Garth Ennis é um dos mais reconhecidos escritores de quadrinhos atuais, cuja marca principal são seus arcos completos de histórias, com personagens que desenvolvem-se durante a trama, não somente acompanhando-a, mas reagindo a elas sob a forma de experiências. Nascido na Irlanda do Norte em 1970, inicia sua carreira com a série Troubled souls (com John McCrea) e True Faith, publicadas na revista inglesa Crisis. Passou a escrever histórias para Judge Dredd e em 1991 foi contratado pela DC Comics para escrever um arco de Hellblazer (arco em que depois será baseado o filme Constantine). Em 1995 cria Preacher com o ilustrador Steve Dillon, seu maior sucesso e um dos quadrinhos mais vendidos da década, junto com Hitman, outra criação dos dois, seu primeiro trabalho que se passa no universo de heróis da DC. Recebeu o Eisner Award de Melhor Escritor em 1998 (LIGA HQ!, 2012).

Em 2001 passou a escrever também para a Marvel, escrevendo para personagens como o Justiceiro, Homem Aranha e Nick Fury. É neste período que Ennis cria The BOYS, em parceria com Darick Robertson, que recém encerrara Transmetropolitan, cocriação sua com o escritor Warren Ellis. As suas seis primeiras edições foram publicadas em 2006 pela Wildstorm, sendo cancelada em janeiro do ano seguinte. A Wildstorm é um selo subsidiário da DC Comics, que forçou o cancelamento de The BOYS. No mês seguinte a série foi acolhida pela Dynamite Entertainment, propondo lançar 72 edições, em uma série de 22 arcos. A série foi indicada para os seguintes prêmios: Melhor série de continuidade no Eisner Award 2008, Quadrinho do ano por menos de 3 dólares na Diamond Comic Distributors Gem Awards 2009 e Melhor quadrinho ou novela gráfica no Scream Awards 2010 (WIKIPEDIA, 2012).

Darick Robertson tem mais de vinte anos como artista na indústria de quadrinhos, tendo trabalhado para Marvel, DC, Vertigo e outras companhias menores, como Malibu Comics, Acclaim, Eclipse e Innovation. Seu primeiro trabalho de destaque foi como desenhista de Space Beaver, o único título lançado pela Tibor Sardy's Ten Buck Comics, e que lhe rendeu, logo aos 21 anos, a oportunidade de trabalhar na Liga da Justiça na DC Comics. Depois foi para a Marvel, passando a trabalhar com personagens como Wolverine, Homem-Aranha e os Novos Guerreiros. Foi convidado para trabalhar com Warren Ellis no projeto The Man of the Atom pela Acclaim, que levou a parceria dos dois em Transmetropolitan. Esta série iniciou-se em 1997 e foi concluída em 2002, e mesmo tendo problemas com as editoras (originalmente foi publicada pela Helix, subsidiária da DC Comics para ficção científica, passando a partir da edição 13 a ser publicada pela Vertigo), foi um grande sucesso, conquistando o prêmio de Novela gráfica da década da revista Wired em 2002. Neste ano trabalhou com personagens da Marvel como HomemAranha e Wolverine, e pela primeira vez com roteiros de Ennis para o personagem Nick Fury, premiado pela revista Rolling Stone. A parceria repetiu-se com Justiceiro no arco Punisher: born. Em 2006 desliga-se definitivamente da Marvel para trabalhar em The BOYS (ROBERTSON, 2012). 


\section{THE BOYS E O COMPLEXO-INDUSTRIAL-MILITAR}

The BOYS é uma série adulta, que retrata a reorganização dos 'rapazes', grupo subvencionado pela Central Intelligence Agency, a CIA, relativamente autônomo por ser secreto, para o mapeamento e combate de 'supers', seres humanos, em sua maioria alterados geneticamente (sejam 'vilões' ou 'heróis') pela transnacional Vought-American Incorporation. Sua trama gira em torno de Hughie 'Mijão', que logo na primeira edição perde sua namorada em um incidente envolvendo um dos 'supers', sendo ela considerada 'dano colateral'. Por recusar um acordo financeiro com Vought American, chama a atenção de Billy 'Açougueiro', que o convida a participar do grupo. Esta história de relacionamentos conflituosos com 'supers' é recorrente à origem de cada um dos integrantes (exceto por Fêmea, experimento governamental, que se insere no grupo por não conseguir conter sua sede de sangue, exceto na presença de Francês, outro membro do grupo, que se completa com 'Leitinho da Mamãe').

O grupo é remontado por decisão direta do presidente dos EUA, Dakota Bob, um republicano representante do complexo industrial-militar-acadêmico 'tradicional', que assim busca coagir a atuação política de seu vice-presidente, Victor K. Neuman, representante da Vought e que busca a qualificação dos 'supers' como armamento de guerra. Este é o mote principal para o conflito entre a Vought e as demais produtoras de armas, disputas que se transpõem para dentro da sociedade política, do Estado em seu sentido estrito. Durante o arco de 6 edições Herogasm (que contou com John McCrea como desenhista convidado), o CEO da Vought, James Stillwell, faz a seguinte fala:

Dakota Bob tem sido bom pro povo dele. Desde Halliburton até o fundo da Blackwater, ele tem passado por eles continuamente. Ele liquidou a maioria do governo federal, e no meio disso tudo, ele entregou o Paquistão... a CIA disse que caçava Bin Laden no Afeganistão, mas Bob apareceu com uma guerra de verdade. Dá pra imaginar o que aqueles contratantes deviam estar armando, fazendo metade do trabalho mal feito e cobrando o dobro do valor de mercado? Aquele homem é uma equipe inteira. (ENNIS; MCCREA; BURNS, 2009, p. 16).

O complexo industrial-militar, como o chamou Dwight Eisenhower em 1961, afirmando estar os EUA reféns deste (ao qual acrescentamos o acadêmico, dada sua confluência com as universidades e instituições de pesquisa estadunidenses, o que acentua inegavelmente o caráter classista da ciência), foi criado nos países capitalistas centrais durante a Primeira Guerra Mundial, como "instrumento disposto e capaz de romper o nó górdio de como combinar a máxima expansão possível com a taxa de utilização mínima", assim "resolvendo" o problema do consumo, questão decisiva para solucionar a crise de superprodução de 1929-33, "apesar de todas as autoglorificadoras mitologias keynesianas e neokeynesianas", sendo que, segundo Istvan Mészaros (2002, p. 685), "foram complementares à expansão desembaraçada do complexo industrial-militar". Osvaldo Coggiola (2011, s/p) nos oferece os seguintes dados sobre o crescimento do complexo industrial-militar-acadêmico durante a Segunda Guerra Mundial: 
Nos Estados Unidos, a produção industrial de armamentos duplicou em cinco anos, perfazendo entre $40 \%$ e $45 \%$ do total da produção, período no qual o setor civil não variou em valor absoluto. Os empregos industriais passaram de 10 para 17 milhões, entre 1939 e 1943. O total de empregos era de 47 a 54 milhões no mesmo período. Se o PNB aumentou de $150 \%$, a concentração econômica espantosa determinou a feição definitiva do capital monopolista nos Estados Unidos - 250 sociedades industriais passam a controlar $66,5 \%$ da produção total, uma percentagem equivalente àquela controlada por 75 mil empresas antes da guerra. As exportações dos Estados Unidos passaram de pouco mais de 5 bilhões de dólares, em 1941, para quase 14,5 bilhões, em 1944. No período 1938-1944, a produção de guerra passou de 2 para 100 nos Estados Unidos; de 4 para 100 na Inglaterra; de 16 para 100, na Alemanha; de 8 para 100 no Japão. A transformação das economias capitalistas em economias de guerra e os diversos pontos de partida para atingir tal objetivo determinam, em última instância, a superioridade dos Aliados: calcula-se em 80 bilhões de dólares o valor do material de guerra produzido pelos Estados Unidos, pela Inglaterra e pelo Canadá, no período anterior ao desembarque de 6 de julho de 1944. No mesmo período, a Alemanha e seus aliados tiveram uma produção equivalente a 15 bilhões.

O complexo industrial-militar-acadêmico foi muito bem sucedido para o desenvolvimento capitalista pela sua capacidade de acabar com a distinção entre consumo e destruição, oferecendo "uma solução radical para uma contradição inerente ao valor que se autodefine como tal em todas as suas formas" (MESZAROS, 2002, p. 687). Este complexo fornece a capacidade de consumo e desperdício ilimitado, sem estar atrelado ao consumidor, "com todas as limitações naturais, socioeconômicas e até culturais de seus apetites" (Idem, p. 687), estando atrelado à defesa da pátria, de "um modo de vida":

[...] ao contemplar a antiga prática romana do "desperdício conspícuo" na forma do "devorar saladas de pérolas", torna-se irresistível a conclusão de sua decadente gratuidade; enquanto, ao contrário, consegue-se legitimar como dever patriótico absolutamente inquestionável o verdadeiro desperdício ilimitado de "devorar" recursos equivalentes a bilhões de tais saladas através dos anos, enquanto milhões incontáveis têm de suportar a inanição como o "destino" do qual não podem escapar. Do mesmo modo, em relação ao segundo aspecto vital, o complexo militar-industrial remove com sucesso as restrições tradicionais do círculo de consumo definido pelas limitações do apetite dos consumidores [...] aloca uma parte maciça e sempre crescente dos recursos materiais e humanos da sociedade a uma forma de produção parasitária e que se autoconsome, tão radicalmente divorciada e, na verdade, oposta à real necessidade humana e seu consumo correspondente que pode divisar como sua própria racionalidade e finalidade última até mesmo a total destruição da humanidade. (MESZAROS, 2002, p. 687-688).

Ele é tão bem sucedido que direciona o sistema para uma nova crise de superprodução, no imediato Pós-Guerra, localizada nos EUA, mas capaz de abalar profundamente o próprio sistema capitalista. Esta crise, segundo Sérgio Lessa, aliada à derrota do 
movimento operário na Europa, foram os elementos confluentes para a constituição do Estado de Bem-Estar. Os EUA tiveram sua produção duplicada a cada dois anos durante a Segunda Guerra Mundial, o que criava uma situação econômica altamente instável para todo mundo capitalista. Aquele país era responsável por metade do PIB industrial e, mesmo tendo uma população equivalente a seis por cento da população mundial, era o consumidor de 30\% de toda a energia do planeta. Esta situação após o término da Guerra só poderia ser remediada com a ampliação drástica do consumo interno e externo aos seus bens de produção, já que não havia mais a escala de consumo destrutivo gerado pelo conflito. Do mesmo modo havia de ser combatida a contenção drástica do consumo ocorrida durante o esforço de guerra e integrar produtivamente os combatentes que voltavam para a vida civil como uma massa de trabalhadores desempregados (LESSA, 2002, p. 279-280).

É na Segunda Guerra que o ‘Lenda', o responsável maior pela criação das histórias em quadrinhos para a Vought, a Victory Comics, autênticos instrumentos de alienação, de justificação ideológica para a verdadeira atuação dos 'supers' naquela realidade - o 'Lenda' seria supostamente baseado em Stan Lee.

Ele inicia sua narrativa sobre a história da transnacional, que teria, ao final do conflito, fornecido caças para os porta-aviões estadunidenses: os Vought American Consolidated F7U pardo:

O pardo era rápido e tinha alcance, mas entrou em serviço precipitadamente, antes que os problemas fossem resolvidos [...] a maldita coisa não podia voar... E isso era apenas a ponta do iceberg. Para aumentar o alcance eles enfiaram tanques de combustível em tudo quanto era lugar. Incluindo um debaixo do assento. O que seria aceitável se o assento fosse ejetável... E foi o que fizeram. Colocaram no topo das coisas para fazer... no próximo modelo. (ENNIS; ROBERTSON, 2008a, p. 2-3).

Estes defeitos, que na trama "mal aparecem nos rodapés dos livros de história" (ENNIS; ROBERTSON, 2008a, p. 4), foram resolvidos pelas articulações políticas da transnacional. Em diálogo com Hughie, o Lenda pergunta-se "porque a Marinha aceitaria o pardo?", para responder: "porque mandaram. De onde veio a ordem? Da comissão de compras. E do Departamento de Guerra. E do Congresso. E de todo o lugar que a Vought American tinha amigos. Todas as campanhas de senadores e representantes que eles bancaram" (ENNIS; ROBERTSON, 2008a, p. 9). E continua:

Ouvi falar que gosta de uma teoria da conspiração. Bem, essa é "a" conspiração, rapaz. E essa não é sobre deuses antigos, aliens ou códigos na nota de um dólar. Nem mesmo sobre um segredo, é algo que as pessoas comuns fazem todos os dias da semana. Negócios [...] Grumman, a General Motors e a Colt fazem isso hoje - e vou repetir, o mais importante de tudo: não existe segredo nenhum. Vá lá fora nas ruas e grite: "economia de guerra". Grite "complexo industrial militar". E me diga que alguém não vá dizer, "é, e daí?". Este é o segredo. Pra falar a verdade, é o único segredo que há para você descobrir. (ENNIS; ROBERTSON, 2008a, p. 8-9). 
Neste sentido atentemos para a generalização deste tipo de procedimento no Pós-Guerra. Para garantir o consumo externo, foi implementado o Plano Marshall, que investiu cerca de 13 bilhões de dólares na Europa, onde 70\% dos produtos consumidos eram de procedência estadunidense. Do mesmo modo, o Japão recebeu investimentos pesados para sua reconstrução. Mas, como Lessa sublinha, mesmo com “esta canalização de gigantescos recursos, os resultados serão ainda muito tímidos para afastar a ameaça de superprodução”. Então a expansão do complexo será intrínseco ao desenvolvimento do capital, sendo que logo "os Estados Unidos se lançam na Guerra da Coréia (1954-56) e, logo depois, substituem a França na Guerra do Vietnã (1958-1975)” (LESSA, 2002, p. 280). E é sobre a intervenção dos EUA no Vietnã que a trama prossegue:

E “olá" para o rifle de assalto M-20, a última novidade da divisão de armas da V.A.C. [Vought American Consolidated] A gota que quase transbordou o copo [...] No final de sessenta e nove, houve a batalha do vale Ia Drang - e os nossos rapazes enfrentaram cara-a-cara os congs pela primeira vez... Estavam cercados e em menor número, mas não estavam perdidos. Eles tinham mil homens, suporte aéreo e de artilharia... Droga, eles teriam sido capazes de varrer o inimigo, eles venceriam com certeza. Depois de uma semana, unidades americanas chegaram em Ia Drang. A primeira coisa que eles viram foram mil cabeças cortadas. E fincadas bem no meio delas, eles viram... (ENNIS; ROBERTSON, 2008a, p. 14-15).

Na imagem seguinte veem-se os soldados empalados em suas armas.

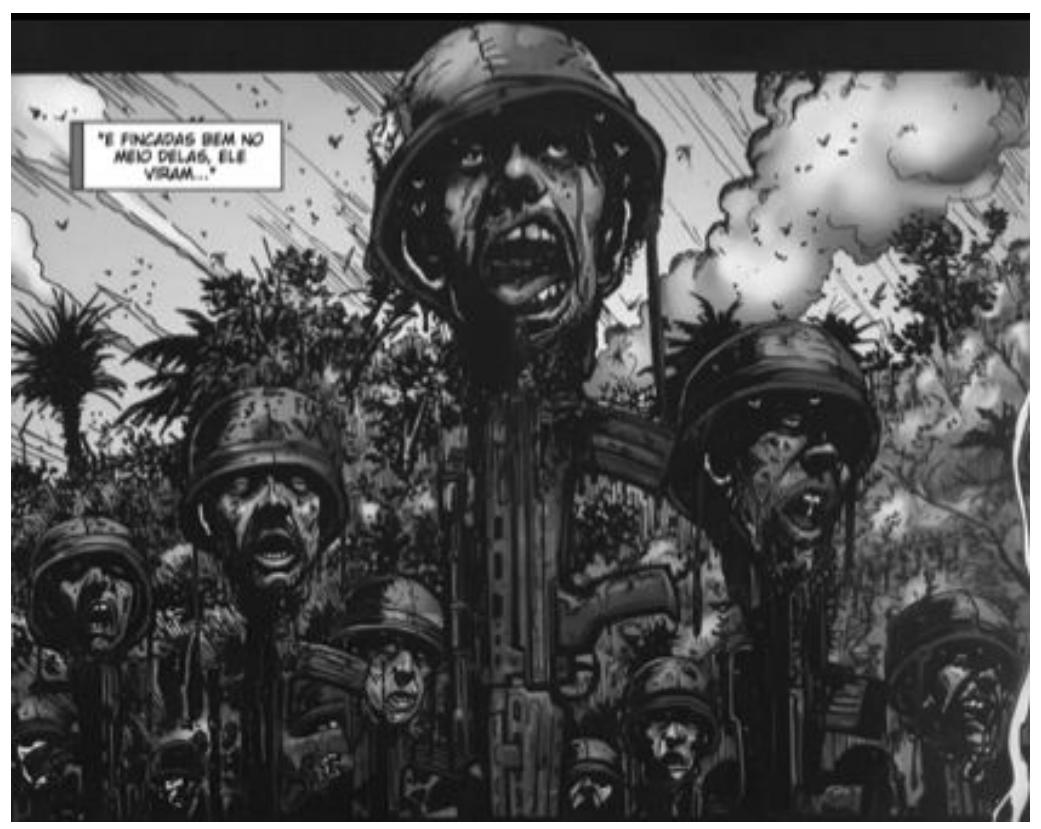

Este tipo de conflito pode ser relacionado com a expansão massiva, a partir da década de 1950, das transnacionais em direção aos países do Terceiro Mundo, buscando diminuir seus custos de produção pelo uso da mão de obra e das matérias-primas destes países. Lessa interpreta esse movimento inicial como "válvula de escape" da discre- 
pância entre produção e consumo, tornada mais grave pela saturação do mercado para determinados produtos, como o de automóveis. Nestes países periféricos que, como já assinalado, tornaram a contrarrevolução preventiva o modo normal de manutenção e ampliação da reprodução das relações sociais capitalistas, o Estado de exceção foi a forma normal da dominação burguesa durante maior parte do restante do século:

Longe de ser surpreendente ou paradoxal, isto revela uma conexão necessária, pois o complexo militar-industrial do capital desenvolvido necessita desesperadamente de canais econômico-militares, impossíveis de obter prontamente, por uma série de razões, dentro dos limites e das modalidades de legitimação de sua própria base doméstica. Assim, apesar da retórica dos "direitos humanos" e da "aliança para o progresso", somos aqui apresentados a uma relação de complementaridade essencial, na qual a oferta perniciosa do complexo industrial-militar "avançado" não consegue gerar internamente a "demanda efetiva" requerida numa escala sempre crescente. (MESZAROS, 2002, p. 693).

Um dos marcos para a afirmação do complexo foi a criação da doutrina do "desenvolvimento com segurança" por técnicos do Massachussets Institute of Technology (MIT) para manter o domínio sobre a América Latina e "evitar que o fantasma do regime comunista pairasse sobre a região e colocasse em risco sua área de influência" (MELLO, 2004, p. 46). Este desenvolvimento tinha como premissa a orientação externa das medidas econômicas e que, com o programa Aliança para o Progresso, só tornou evidente a militarização das relações imperialistas (Idem, p. 46). A narrativa da Lenda prossegue com as consequências sociais internas nos EUA daquele massacre no Vietnã:

Assim que história veio a público houve reações e a falta de sorte da Vought foi que Bobby Kennedy em pessoa foi atrás deles. Ele procurava por uma plataforma, uma cruzada - L.B.J. [Lyndon Baines Johnson, vice de Kennedy, assumiu a presidência após seu assassinato] se convenceu que seria o próximo depois do Vietnã e nada fez quando Bobby atacou a Vought. Documentos vazaram. Uma comissão de inquérito foi nomeada. As relações públicas da Vought levaram no rabo o verão todo. Quando as transmissões dos últimos contatos com Ia Drang foram ao ar, ninguém em Washington poderia salvá-los. É o jogo, então foda-se... [...] E todos viveram felizes para sempre. (ENNIS; ROBERTSON, 2008a, p. 16).

Após três anos, a companhia retornaria como Vought-American, oferecendo um novo 'produto', um 'super': o Patriota, a versão de Ennis e Robertson para o SuperHomem. Fruto de uma gravidez forçada em uma garota declarada mentalmente incapaz na qual foi injetado o 'composto $V^{\prime}$ ', depois do seu nascimento teria sido treinado para obedecer "amarrado em uma bomba $\mathrm{H}^{\prime}$.

Este composto seria obra de um cientista alemão, Jonah Vagelbaum, durante o Reich: "a V.A.C. tinha tirado ele da Alemanha nos anos 30 - a família devia ter se juntado a ele nos EUA, mas alguém fudeu tudo e eles morreram nos acampamentos" (ENNIS; ROBERTSON, 2008b, p. 4). O que ecoa a história de exílio de uma geração de cientistas e pesquisadores que fugiram do nazismo, exilando-se na Inglaterra ou nos EUA, mas 
neste caso nos serve para desvelar o incentivo estatal à pesquisa e desenvolvimento do complexo. Segundo Carlos Medeiros:

O "complexo militar-industrial-acadêmico" gerou, em diferentes momentos, um estímulo tanto de demanda quanto de oferta ao processo de inovações e criou uma rede descentralizada e coordenada de instituições e comunidades tecnológicas sem rival no mundo contemporâneo. Dada esta característica específica, a influência dos militares na tecnologia não foi circunscrita à provisão de recursos ao processo de $\mathrm{P \& D}$ [Pesquisa e Desenvolvimento] e às compras de governo aos fabricantes de armas, mas incluiu a montagem de instituições voltadas ao deslocamento da fronteira científica e à aceleração do progresso tecnológico. Mais do que as armas criadas por este esforço, este objetivo político tornou-se um traço marcante da ciência e tecnologia americana. (MEDEIROS, 2004, p. 226).

Somente o MIT, nos anos que se seguiram à guerra, recebeu cento e dezessete milhões de dólares para pesquisa e desenvolvimento, o California Institute of Technology (CALTECH), oitenta e três milhões, a AT\&T, dezessete milhões, e a General Eletric oito milhões - que, junto com outras fabricantes de armas, como a Lockheed, Westinghouse, IBM, Boeing, a General Dynamics, foram privilegiadas por estes investimentos (MEDEIROS, 2004, p. 232-233).

Na trama a Vought torna-se monopólio do setor após o suicídio de Vagelbaum e a dificuldade de obtenção do grau de pureza, que faria custar dezenove bilhões de dólares a dose utilizada na fabricação dos "Sete", o principal grupo de 'supers' da empresa, semelhante à Liga da Justiça original (naquele contexto a URSS teria criado seu próprio programa e grupo de 'supers', chamado de "Glorioso Plano de Cinco Anos") (ENNIS; ROBERTSON, 2012, p. 14): “fizeram isso sete vezes [...] A Vought afinal tinha algo com que poderia trabalhar. Eles sabiam como jogar com o sistema, eles tinham costurado tudo muito bem - mas até então eles só tinham merda como produto. Agora, não mais" (ENNIS; ROBERTSON, 2008a, p. 17). Assim, os 'rapazes' seriam não somente um grupo de combate aos 'supers' (são exploradas motivações pessoais de cada um de seus integrantes para tanto), mas para a manutenção aberta da sociedade de classes. Quando o Açougueiro, um dos membros antigos que passa à liderança na reestruturação do grupo, está tentando convencer Hughie a juntar-se à equipe, há um diálogo relevante entre estes:

- Hughie, nem mesmo nos seus sonhos mais loucos esses babacas poderiam governar o mundo. E não são as sociedades secretas, não são os illuminati ou departamento $X$ se reunindo em algum ligar que ninguém sabe onde fica. Não é nenhum deles. É só a boa e velha companhia. Caras gordos e nerds sentados em seus escritórios tentando achar meios de espionar as pessoas. Fazendo nada além de manter o mundo exatamente do jeito que é. O que significa poder na mão dos poderosos. Significa manter o status quo. - E não há nenhuma ameaça maior ao status quo do que super-heróis... (ENNIS; ROBERTSON, 2008, p. 13). 


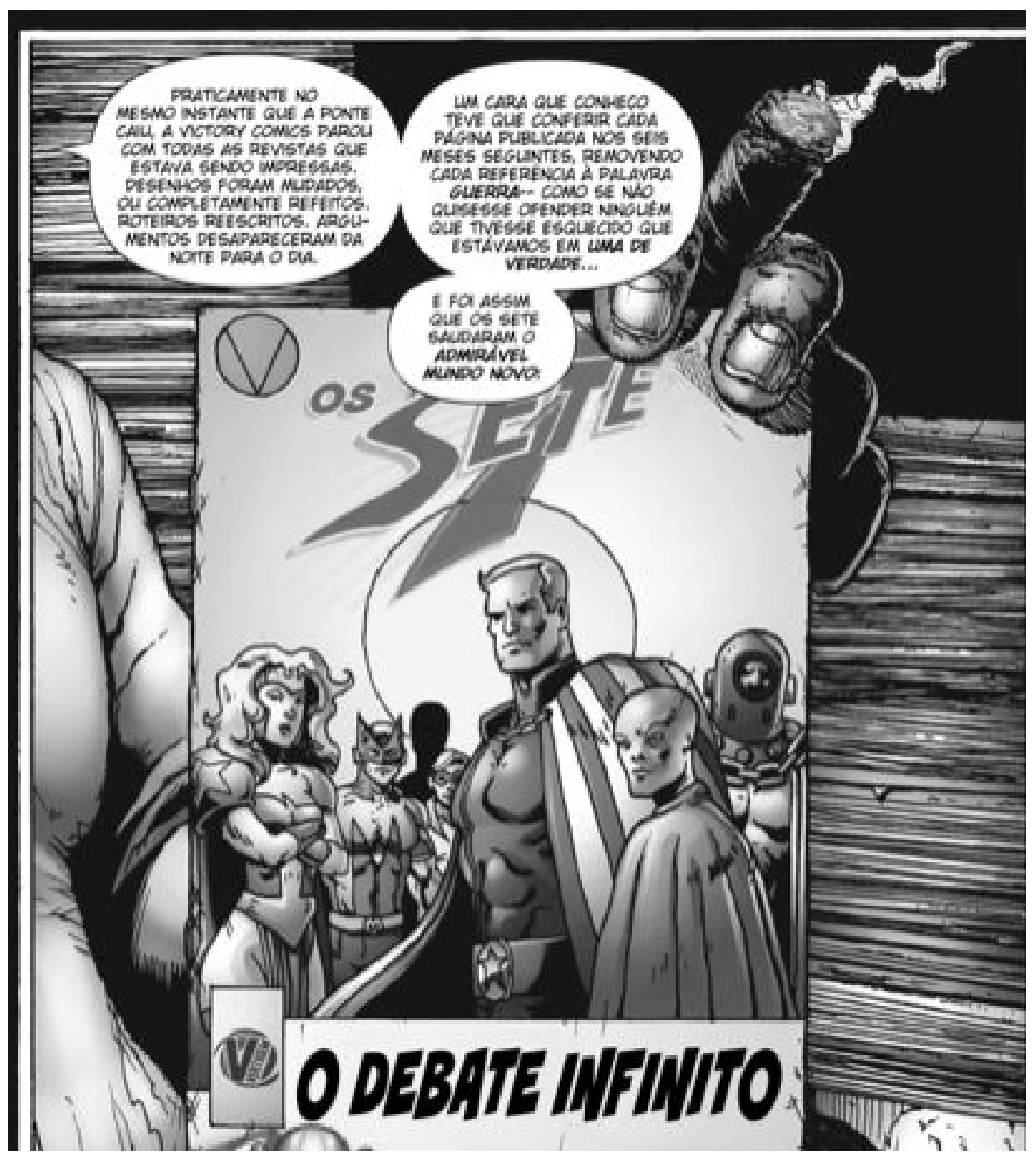

O que se repete na fala final do Lenda, na edição 19, quando explicita a posição da Vought American e de seus 'supers' em relação ao sistema, especialmente no que se refere ao consentimento passivo dos segundos. Quando Hughie pergunta "se os supers são assim tão poderosos, porque eles não se juntam e conquistam o mundo?", o Lenda responde:

Quê, tá brincando...? Por que as pessoas obedecem a lei? Para que a sociedade fique do jeito que é. Porque é assim que fica mais confortável para todos. E é o mesmo para os supers... Quem governasse o mundo teria que ser um filho da puta, principalmente por desfrutar das vantagens de ser tão poderoso do jeito que já é hoje. Por isso temos mais super-heróis que vilões - porque eles sabem reconhecer uma coisa boa quando a encontram. Porque o status quo funciona. Que é quando exatamente começam os problemas. O público não tem o suficiente dos sete. A Vought está fazendo dinheiro a rodo - eles têm uma marca tão boa quanto a bandeira, eles têm que ter. O que eles não têm mais é competição... Número um numa corrida de um só. Eles deixaram as outras corporações caírem por terra. Mas os outros não são tolos. Eles sabem que a 
Vought está fazendo e agora estão prontos para enfrentá-los. Negócios... lembra? Exceto que todos os outros são fornecedores da defesa. Que é onde o dinheiro graúdo está. (ENNIS; ROBERTSON, 2008a, p. 25-16).

Exatamente este lucro encontra-se nas condições que o complexo cria e que já pontuamos. Através da "legitimação da oferta real pela 'demanda fictícia'" o capital acaba por encontrar um novo modo de conduzir e "administrar as consequências objetivas do desenvolvimento socioeconômico, incluindo suas próprias contradições no plano da interação crucial entre produção e consumo, minimizando, por todo um período histórico" - e tendo seu aspecto mais bem sucedido durante as erupções de crises (MESZAROS, 2002, p. 693), já que significa o afastamento de mais de um terço da economia total das flutuações próprias do mercado (MESZAROS, 2002, p. 806).

O que, sem dúvida, tem aspectos intrínsecos com a posterior ofensiva do capital, quando nenhuma característica positiva esperada pelo desenvolvimento das relações sociais capitalistas será concretizada. O autor faz questão de deixar isto explícito:

[...] a tendência anterior à realização de suas precondições mais elementares sofre um grave retrocesso, mesmo nos países capitalistas mais "avançados", quando a linha de menor resistência do capital, em vez de englobar a totalidade da humanidade na busca efetiva da industriosidade geral e da produtividade genuína, começa a estipular a brutal ejeção de um número crescente de pessoas do processo de trabalho. A mesma reversão se aplica ao desenvolvimento da ciência e à transformação das práticas produtivas de acordo com suas potencialidades inerentes, que supostamente deveriam favorecer a expansão do valor de uso e a interação dialética da progressiva expansão do valor de uso com o desdobramento das necessidades humanas. Como resultado das novas exigências e determinações do capital, a ciência é desviada de seus objetivos positivos, e a ela é designado o papel de ajudar a multiplicar as forças e modalidades de destruição, tanto diretamente, fazendo parte da folha de pagamento do complexo industrial-militar ubíqua e catastroficamente perdulário, como indiretamente, a serviço da "obsolescência planejada" e de outras engenhosas práticas manipuladoras, divisadas para manter os lobos da superprodução longe das portas das indústrias de consumo. (MESZAROS, 2002, p. 694).

Estes desdobramentos do capital citados acima, a obsolescência programada, articulada à chamada 'reestruturação produtiva' (DIAS, 2003), são derivados das mudanças sociais do período, relativas ao processo de estabelecimento do capital-imperialismo (ou capitalismo imperialista de dominância monetária), do "imperialismo [que] dissolvia-se no capital-imperialismo que gerara e nutrira" (FONTES, 2011, p. 194), ou seja, o esgotamento da arquitetura econômica do Pós-Guerra através da sua reprodução ampliada. Esgotamento que de maneira alguma irá prescindir do complexo industrial-militar, mas, pelo contrário, irá ampliá-lo, especialmente nos grandes momentos de crise, o que pode ser observado tanto na década de 1970 quanto nos desdobramentos da atual crise. 


\section{CONSIDERAÇÕES FINAIS}

Pensar criticamente sobre o complexo industrial-militar, um aspecto que costuma ser ignorado (propositadamente ou não) nas análises econômicas e sociais sobre o capitalismo e suas crises, nos permite visualizar relações que não são possíveis de serem obscurecidas pela ideologia, especialmente nos desdobramentos entre o Estado, a sociedade civil, as empresas transnacionais e o imperialismo. E alguns dos maiores mitos que dão sustentação para a dominação política dos sujeitos históricos são relativos às funções do Estado na sociedade de classes, sendo diversas as interpretações ideológicas deste, que não dão conta das complexidades que este possui e nem das relações sociais que o sustentam: o Estado como sujeito, instrumento, 'neutro', 'acima das classes', além de caracterizações 'dimensionais' como 'inchado', 'mínimo', etc. Iremos compreender o Estado capitalista como uma condensação material de uma relação de forças, perpassado pela luta entre as classes e frações de classes (POULANTZAS, 2000, p. 185), sua materialidade institucional sendo marcada pelas relações sociais de produção e pela divisão social do trabalho. Através de seu conjunto de aparelhos sustentados pela divisão entre trabalho manual e intelectual, e a atuação dos últimos relacionada diretamente com a dominação política - a "legitimação de práticas do Estado e de seus agentes como portadores de um saber particular, de uma racionalidade intrínseca..." (POULANTZAS, 2000, p. 64). Pelo fato de o Estado ser um produtor de hegemonia (em sua relacionalidade com a sociedade civil, lócus de atuação dos aparelhos privados de hegemonia, não contraposta a esta) cumpre tarefa fundamental na disseminação de valores, representações, ideias para a reprodução ampliada do estado de coisas. E mesmo que pesquisas recentes busquem dar conta do enredamento do complexo industrial-militar e sua expansão, seja em suas terceirizações, como analisado por Alexandre Arienti Ramos (2011), ou em suas ramificações biotecnológicas, estudadas por Douglas Rundvalt (2012), ainda existe muito a ser explorado e investigado. Neste sentido este texto propõe-se acréscimo introdutório sobre a questão em sua abordagem midiática, no caso específico dos quadrinhos.

Quadrinhos são objetos políticos, imersos na ideologia histórica que os condiciona em seu conteúdo e marcado pelas determinações do mercado em seu formato. Tem uma natureza de objeto de encontro, zona de intersecção entre o verbal e o visual, sendo, ao mesmo tempo uma obra de características artesanais na sua gênese, cuja autonomia relativa pode conceber obras críticas, agudas, de brilhantismo único, como a analisada aqui, que forçam conflitos entre os detentores do poder de reproduzir e veicular estas produções em massa, que apontam brechas e denunciam a própria indústria cultural, sem que com isso sejam carregadas de cinismo ou conformismo, proporcionando "uma espécie de verdade - não, temos que admitir, uma verdade científica ou teórica, mas a verdade de como os homens vivem e compreendem suas condições de vida, e de como eles protestam contra elas" (EAGLETON, 2011, p. 132).

É uma cultura da abstração, como chama atenção Fredric Jameson (2006) que reproduz no âmbito da cultura o enleio - do qual a base produtiva faz parte - em que a linguagem midiática prevalece, assumindo um caráter universal. Esse movimento des- 
territorializa as questões e permite que a problematização proposta pela obra assuma um sentido mais geral: a identificação se dá pela situação, pelo personagem, em maior nível do que pelo local que a origina ou a que se referem os autores. A transformação da cultura, ou a 'globalização cultural', tem se apresentado como uma estratégia central de garantia desta 'nova' ordem, o que não rompe com a homogeneização pelo consumo, já proposta por Adorno. Entretanto, cabe chamar a atenção para uma ética, valores e conceitos de espaço e tempo partilhados, que vão além da dimensão exclusivamente econômica, em uma nova instância de socialização desta cultura (ORTIZ, 1998, p. 144). The BOYS é um exemplo desse processo, uma vez que um quadrinho estadunidense acaba por ampliar suas pretensões de discussão local frente às múltiplas traduções (citamos aqui a edição brasileira) e as articulações específicas que a obra ficcional permite, no escopo dos seus leitores, em uma tensão que questiona ao mesmo tempo que reafirma uma ordem social voltada para o consumo.

Em The BOYS esse conflito é especialmente premente exatamente por buscar superar os limites impostos pela forma, em relação ao que se espera de obras ficcionais de seu mercado de origem. Sua produção está marcada por problemas com a indústria de quadrinhos, questão que é dissolvida na acusação relativa ao caráter sexual e violento da obra em questão. Não que estes elementos não estejam presentes em profusão, mas diversas obras adultas também o fazem sem com isto receberem sanções ou, neste caso, o abandono da publicação da obra por parte de sua editora, vide-se Hack/Slash da Image ou Enigma da DC/Vertigo, dentre vários exemplos possíveis. Obras como The BOYS localizam-se no entretempo, sendo capazes de deslizar por entre as fissuras do imediato, realocando-se em diversos discursos, afirmando-se como parte da realidade, mas igualmente assumindo um distanciamento que permite ao leitor a compreensão das estruturas condicionantes da sua própria existência. Unindo o real e o ficcional, traduzem e espelham em si os conflitos e as contradições da sociedade, extraindo criatividade dos contrastes coexistentes naquele todo, adaptando o diferente e criando o novo, alterando e construindo novas percepções de mundo.

\section{REFERÊNCIAS}

\section{Fontes}

ENNIS, Garth; MCCREA, John; BURNS, Keith. Herogasm. n. 3. Nova Iorque: Dynamite Entertainment, Novembro 2009.

ENNIS, Garth; ROBERTSON, Darick. The BOYS. n. 2. Nova Iorque: Dynamite Entertainment, Março 2008. ENNIS, Garth; ROBERTSON, Darick. The BOYS. n. 11. Nova Iorque: Dynamite Entertainment, JunhoJulho 2012.

ENNIS, Garth; ROBERTSON, Darick. The BOYS. n. 19. Nova Iorque: Dynamite Entertainment, Outubro 2008a.

ENNIS, Garth; ROBERTSON, Darick. The BOYS. n. 20. Nova Iorque: Dynamite Entertainment, Outubro $2008 b$. 


\section{Bibliografia}

Livros:

ADORNO, Theodor W.; HORKHEIMER, Max. A dialética do esclarecimento. Rio de Janeiro, Jorge Zahar, 1985.

BENJAMIN, Walter. "A obra de arte na época de sua reprodutibilidade técnica". In: LIMA, Luiz Costa (org.). Teoria da cultura de massa. São Paulo: Paz e Terra, 2000.

CARDOSO, Ciro Flamarion; VAINFAS, Ronaldo. Novos domínios da história. Rio de Janeiro: Elsevier, 2012.

EAGLETON, Terry. Marxismo e crítica literária. São Paulo: UNESP, 2011.

EISNER, Will. Quadrinhos e arte sequencial. São Paulo: Martins Fontes, 1989.

GRAMSCI, Antonio. Cadernos do cárcere. Volume 1. Rio de Janeiro: Civilização Brasileira, 1999.

GRAMSCI, Antonio. Cadernos do cárcere. Volume 2. Rio de Janeiro: Civilização Brasileira, 2004.

GRAMSCI, Antonio. Cadernos do cárcere. Volume 4. Rio de Janeiro: Civilização Brasileira, 2001.

JAMESON, Fredric. A virada cultural: reflexões sobre o pós-modernismo. Rio de Janeiro: Civilização Brasileira, 2006.

KLAWA, Laonte; COHEN, Haron. "Os quadrinhos e a comunicação de massa”. In: MOYA, Álvaro de. Shazam. São Paulo: Perspectiva, 1977.

LESSA, Sérgio. Trabalho e proletariado no capitalismo contemporâneo. São Paulo: Cortez, 2002.

MEDEIROS, Carlos Alberto de. “O desenvolvimento tecnológico americano no pós-guerra como um empreendimento militar". In: FIORI, José Luis. (org.). O poder americano. Petrópolis: Vozes, 2004.

MENDONÇA, Sonia Regina de; FONTES, Virgínia. "História e teoria política”. In:

MESZAROS, Istvan. Para além do capital. São Paulo: Boitempo, 2002.

ORTIZ, Renato. Mundialização e cultura. São Paulo: Brasiliense,1998.

POULANTZAS, Nicos. O Estado, o poder, o socialismo. São Paulo: Paz e Terra, 2000.

\section{Teses e dissertações}

MELLO, Noval Benayon. Subdesenvolvimento, imperialismo, educação, ciência e tecnologia no Brasil: a subordinação reiterada. Tese de Doutorado (Doutorado em Educação). Niterói: UFF, 2004.

\section{Revistas}

COGGIOLA, Oswaldo. "O sentido histórico da Segunda Guerra Mundial". Olho da história, Salvador, n . 1, 1995. Disponível em: http:/ / www.oolhodahistoria.ufba.br/01sentid.html. Acesso em: 01.06.12.

DIAS, Edmundo Fernandes. "Reestruturação produtiva: forma atual da luta de classes". Outubro, São Paulo, no. 1, 2003. Disponível em: http://www.revistaoutubro.com.br/edicoes/01/out01_03.pdf, Acesso em: 16.10.11.

QUINIOU, Yves. “Das classes à ideologia: determinismo, materialismo e emancipação na obra de Pierre Bourdieu". Crítica Marxista, Campinas, no. 11, 2000. Disponível em: http://www.unicamp.br/cemarx/ criticamarxista/02quinio.pdf, Acesso em: 13.03.13.

RAMOS, Alexandre Arienti. “Os Estados Unidos e o fomento ao mercenarismo (2001-2009)”. História e luta de classes, Marechal Cândido Rondon, nº. 11, 2011.

RUNDVALT, Douglas; ALBUQUERQUE, Edu Silvestre de. "Complexo industrial-militar-farmacêutico e a construção da hegemonia norte-americana no séc. XXI". Revista de Geopolítica, Natal, v. 3, nº 1, jan./jun. 2012. Disponível em: http://www.revistageopolitica.com.br/ojs/ojs-2.2.3/index.php/rg/issue/view/7/ showToc, Acesso em: 13.04.13. 


\section{Sítios}

ENNIS, Garth; ROBERTSON, Darick. The boys. nº. 7. Cover. Disponível em: http:/ / www.badhaven.com/ wp-content/uploads/2012/08/legend.jpg, Acesso em: 11.04.13.

JETRO. “Cool” Japan's economy warms up. Março, 2005. Disponível em: http://www.jetro.go.jp/en/ reports/market/pdf/2005_27_r.pdf, Acesso em: 13.04.13.

LIGA HQ! Garth Ennis. Disponível em: http://ligahq.com.br/especial.php?especial=19 Acesso em:.

MUNDOHQ. O leitor brazuca de HQ é assim. Disponível em: http://www.mundohq.com.br/site/ detalhes.php?tipo=19 Acesso em: 11.04.13.

ROBERTSON, Darick. About. Disponível em: http://darickrobertson.com/about/ Acesso em: 19.06.12.

WIKIPEDIA. The boys (comics). Disponível em: http://en.wikipedia.org/wiki/The_Boys_(comics) Acesso em: 30.05.12.

Recebido em 26-04-2013

Aceito para publicação em 31-01-2014 